\title{
Helianthus annuus L. Yapraklarında Tuz Stresi, Bazı Bitki Hormonları ve SNP Uygulamalarının Sinyal Moleküllerine Etkisi
}

\author{
Oğuz Ayhan Kireçci ${ }^{\mathscr{P}}$ (D), Füsun Yürekli2 ${ }^{\text {ID }}$ \\ ${ }^{1}$ Bitlis Eren Üniv., Hizan Meslek YO Bitkisel ve Hayvansal Üretim Böl., Bitlis, ${ }^{2}$ İnönü Üniv., Fen-Edebiyat Fak., Biyoloji Böl., Malatya \\ $\bowtie$ : kireccioguzayhan@gmail.com
}

\section{ÖZET}

$\mathrm{Bu}$ çalışmada tuz stresi, sodyum nitroprussid ve hormon uygulamalarının Helianthus annuus L. cv. Tarsan-1018 ayciçeği bitkisi yapraklarındaki bazı sinyal moleküllerine etkileri araştırılmıştır. Helianthus annuus L. cv. Tarsan-1018 tohumları Edirne Trakya Tarımsal Araştırma Enstitüsü'nden temin edilmiştir. Tohumlar kültür çözeltisi ile 5 hafta boyunca sulanmıştır. Beşinci haftanın sonunda tuz, sodyum nitroprussid ve hormon uygulamaları 72 saat boyunca yapraktan uygulamayla gerçekleştirilmiştir. 24 ve 72 . saatler sonunda numuneler alınmıştır. Ayçiçeği yaprak dokularının (Helianthus annuus L. cv. Tarsan-1018) tüm sinyal moleküllerinin analizi, analiz kiti kullanılarak belirlenmiştir. Tuz stresi, sodyum nitroprussid ve hormon uygulamaları NO miktarını artırmıştır. IAA ve GA'nın uygulanmasina devam edilmesi, cGMP ve Ca+ 2 miktarında bir azalmaya neden olmuştur. Bunların yanı sıra tuz stresi, sodyum nitroprussid ve hormon uygulamaları kontrol grubundan daha yüksek NO, cGMP ve Ca+ 2 miktarları sağlamıştır. Sonuçlar, hormonlar ve sinyal molekülleri arasında sinerjik bir etki olduğunu göstermiştir. Sinyal moleküllerinin stres koşullarına karşı düzenlendiği gözlenmiştir.
DOI:10.18016/ ksudobil.397612

\author{
Makale Tarihçesi \\ Geliş Tarihi : 22.02.2018 \\ Kabül Tarihi : 09.05.2018
}

Anahtar Kelimeler

Bitki hormonları,

Kalsiyum,

Nitrik oksit,

Siklik guanozin monofosfat,

Tuz stresi

\section{Araştırma Makalesi}

The Effect of Salts Stress, Some Plant Hormones and SNP Applications on Signal Molecules in

\section{Helianthus annuus L. Leaves}

\section{ABSTRACT}

In this study, the effects of salt stress, sodium nitoprusside and hormones applications on some signal molecules [nitric oxide (NO), cyclic guanosine monofosfate (cGMP) and calcium $(\mathrm{Ca}+2)]$ of sunflower (Helianthus annuus L. cv. Tarsan-1018) plant leaf were investigated. Helianthus annuss L. cv. TARSAN - 1018 seeds were obtained through the Edirne Thrace Agricultural Research Institute. Seeds were irrigated with culture solution for 5 weeks. At the end of the fifth week salt, sodium nitoprusside and hormone applications were performed with foliar application for 72 hours. At the end of 24th and 72nd hours samples were taken. All of signal molecules of leaf tissues of sunflower (Helianthus annuus L. cv. Tarsan-1018) were determined by using analysis kit. Salt stress, sodium nitroprusside and hormone applications caused an increase in the level of NO. Continuation of the administration of IAA and GA resulted in a decrease in the amount of cGMP and $\mathrm{Ca}+2$. Besides of these, salt stress, sodium nitroprusside and hormone applications provided higher NO, cGMP and $\mathrm{Ca}+2$ levels than the control group. The results showed that there was a synergistic effect between hormones and signaling molecules. It has been observed that the signal molecules were regulated against stress conditions.

\section{Article History}

Received: 22.02.2018

Accepted: 09.05.2018

\section{Keywords}

Calcium,

Cyclic guanosine monophosphate,

Nitric oxide,

Plant hormones,

Salt stress

\section{Research Article}

To cite : Kireçci, OA, Yürekli, F 2018. Helianthus annuus L. Yapraklarında Tuz Stresi, Bazı Bitki Hormonları ve SNP Uygulamalarının Sinyal Moleküllerine Etkisi. KSÜ Tarım ve Doğa Derg 21(5): 665-671. DOI:10.18016/ksudobil.397612. 


\section{GIRIŞ}

Biyolojik stres; bitkiler gibi biyolojik sistemlerde normal işlevleri ve oluşumu engelleyen negatif koşullar olarak tanımlanabilir (Jones ve Jones 1989; Gaspar ve ark., 2002; Jaleel ve ark., 2009). Tuzluluk, son yıllarda dünya çapında artmaya devam eden bir stres türüdür. Yüksek tuzluluk; su stresi, iyon toksisitesi, besin yetersizliği, metabolik süreçlerin değişimi, membran kusurları, hücre bölünmesi ve genotoksisite gibi çeşitli olumsuzluklara neden olarak bitkiler üzerinde negatif etkiler gösterir (Zhu, 2007). Tuz stresinin devam etmesi ise; protein sentezi, fotosentez, enerji ve lipid metabolizması gibi önemli fizyolojik aşamaları olumsuz etkiler (Parida ve Das, 2005). Çoğu bitki, tuzluluğun olumsuz etkisine karşı koruyucu ya da sakınıcı mekanizmalara sahiptir. Bu mekanizmalar kuraklık ve tuz stresi ile mücadele eder (Yordanov ve ark., 2000; Valladeres ve Pearcy 2002; Martinez-Ferri ve ark., 2004; Radhakrishnan ve Lee, 2013). Bitkiler abiyotik strese maruz kaldığında, bazı endojen bitki hormonları sinyal iletiminde ve gen ifadesinin düzenlenmesinde önemli rol oynamaktadır (Xiong ve ark., 2002). Absisik asit (ABA), su ve ağır metal stresleri gibi durumlarda strese karşı bitki tepkisinin düzenlenmesinde rol oynar ve aynı zamanda kuraklığa karşı tepkilerin düzenlenmesine izin verir. Abiyotik ve biyotik stres koşullarında stomatal aktivite, uyku hali ve diğer bitki aktivitelerini düzenler (Moore, 1989; Davies ve Jones, 1991; Weyers ve Paterson, 2001; Popko ve ark., 2010). Tuz stresi sirasinda ABA miktarı artar (Szepesi ve ark., 2009). Su yokluğunda oluşan antioksidan savunma, ABA etkinliği ile düzenlenir. (Narusaka ve ark., 2003; Hancock ve ark., 2011). ABA, bazı koruyucu genlerin sentezlenmesine aracılık eder. $\mathrm{Bu}$ nedenle hayati bir hücresel sinyal molekülüdür (Hasanuzzaman ve ark., 2013). İndol-3 asetik asit (IAA), hücre döngüsü, büyüme ve gelişme, vasküler dokuların ve polenin oluşumu gibi olaylarda önemli rollere sahiptir (Davies, 1995; He ve ark., 2000; Ni ve ark., 2002). Oksin seviyeleri ile bitkilerdeki tuz stresi arasındaki etkileşim üzerine çok az rapor olmasına rağmen, araştırmacılar tuz stresi koşullarındaki IAA içeriğinin ABA'yla benzer olduğunu belirlemiştir (Ribaut ve Pilent, 1991). Ayrica, oksinlerin tuz stresine karşı düzenleyici etkileri olduğu da bilinmektedir (Jung ve Park, 2011). Giberellik asit (GA) bitki büyümesini ve gelişimini düzenler. Giberellik asitler, tohum çimlenmesini, yaprak genleşmesini ve kök uzamasını düzenleyen bir hormon grubudur (Magome ve ark., 2004; Kim ve Park, 2008). Nitrik oksit (NO), bitki büyüme ve gelişmesinde etkili bir moleküldür. Abiyotik stres koşulları altında NO'nun antioksidan enzimlerin aktivasyonunda rol oynayabileceği belirtilmiştir. Bazı araştırmacılar, NO'nun antioksidan etkiye sahip olduğunu da ifade etmişlerdir. NO miktarı, bitkilerde tuz stresi toleransına karşı artar (Leshem ve ark., 1998; Beligni ve Lamattina, 2000; Guo ve Crawford, 2005; Libourel ve ark., 2006; Mishina ve ark., 2007). Bitki hücresi gelişiminde NO'nun ana rolü üzerine yapılan çalışmalar; cGMP ve NO'nun rollerinin anlaşılmasına odaklanmıştır. Çalışmalar, kalsiyum, NO ve cGMP arasında bir ilişki olduğunu bildirmektedir (She ve ark., 2004; Neill ve ark., 2008; Wang ve ark., 2010). cGMP sentezi bitkilerde belirlenmiştir ve cGMP sentezinin NO tarafından arttırıldığ (Zhao ve ark., 2007). Mevcut çalışmada, bazı sinyal molekülleri üzerinde tuz stresinin ve ekzojen olarak uygulananan sodyum nitroprussid, ABA, IAA ve GA'nın etkisi açıklanmaya çalışılmış olup bu amaçla nitrik oksit, cGMP ve $\mathrm{Ca}^{+2}$ miktarlarındaki değişimler değerlendirilmiştir.

\section{MATERYAL ve METOD}

\section{Deney Materyali ve Yetiştirme Koşulları}

Araştırma materyali olan Ayçiçeği tohumları (Helianthus annuss L. cv. TARSAN - 1018) Trakya Tarımsal Araştırma Enstitüsü'nden elde edildi. Maksimum tuz konsantrasyonu, ön deneylerle belirlendi. Sonuç olarak $300 \mathrm{mM} \mathrm{NaCl}$ konsantrasyonunun maksimum tuzluluk konsantrasyonu olduğu saptandı ve bu çalışmada tuz stresi oluşturmak için kullanıldı. Sterilizasyon sonrasında, tohumlar karanlıkta 24 saat inkübe edildi. Her grup için 5 saksı hazırlanarak her bir saksıya 40 tane tohum ekildi. Çimlenmeden sonra bitkiler 5 hafta boyunca Hoagland kültür çözeltisi kullanılarak yetiştirildi.

\section{Tuz, SNP ve Bitki hormonlarının Uygulanması}

5. hafta sonunda; sodyum nitroprusid (100 uM), gibberelik asit (100 uM), indol asetik asit (100 uM), absisik asit (100 uM), ile bunlarm diğer kombinasyonları ve tuz stresi 72 saat boyunca yapraktan uygulandı. Yapraklar 24. ve 72. saatlerde rastgele seçildi ve sıvı azot ile dondurularak analizlere kadar $-40{ }^{\circ} \mathrm{C}$ 'de saklandı. NO, cGMP ve $\mathrm{Ca}^{+2}$ analizleri için 10 deney grubu oluşturuldu: Kontrol, $300 \mathrm{mM}$ $\mathrm{NaCl}, 100 \mathrm{uM}$ SNP, $300 \mathrm{mM} \mathrm{NaCl}+100 \mathrm{uM}$ SNP, 300 $\mathrm{mM} \mathrm{NaCl}+100 \mathrm{uM} \mathrm{ABA}, 300 \mathrm{mM} \mathrm{NaCl}+100 \mathrm{uM}$ IAA, $300 \mathrm{mM} \mathrm{NaCl}+100 \mathrm{uM}$ GA, 100 uM ABA, 100 uM IAA ve 100 uM GA.

\section{Nitrik Oksit Tayini}

Ayçiçeği bitkisinin yaprak dokularındaki nitrik oksit değerleri nitrik oksit ölçüm kiti (Biovision, katalog numarası K262-200) kullanılarak 540 nm'de belirlendi.

\section{cGMP Tayini}

Örnek dokulardaki cGMP miktarı, cGMP kiti (Biovision, katalog numarası K372-100) ile 450 nm'de absorbans ile 
belirlendi. Sonuçlar $\mathrm{pmol} / \mathrm{ml}$ olarak ifade edildi.

\section{Kalsiyum Tayini}

Yaprak dokulardaki $\mathrm{Ca}^{+2}$ miktarı 575 nm'deki absorbans değerlerine göre kalsiyum kiti (Biovision, katalog numarası K380-250) kullanılarak mikroplaka okuyucu sistem (Biotech Epoch) vasitasiyla tespit edildi. Sonuçlar $\mu \mathrm{g} / \mu \mathrm{l}$ cinsinden hesapland.

\section{İstatistik Analizi}

Deney sonucunda elde edilen veriler SPSS 15.0 istatistik paket programı ile değerlendirildi. Kontrol grubu ile deney gruplarının ortalamaları arasındaki farklılıklar önce tek-yönlü ANOVA testi ile belirlenirken, her bir grubun diğerine göre farklılıkları ise post hoc LSD testi yapılarak tespit edildi. Değerler ortalama \pm standart sapma (ortalama $\pm \mathrm{SD}$ ) şeklinde belirtildi.

\section{BULGULAR}

\section{Nitrik Oksit Miktarı}

Ayçiçeği bitkisinin (Helianthus annuss L.cv. TARSAN 1018) yaprak dokularındaki nitrik oksit miktarının tüm uygulama gruplarında kontrol grubuna göre daha yüksek olduğu tespit edildi (Tablo 1). $\mathrm{NaCl}$ uygulamasinda elde edilen $\mathrm{NO}$ seviyesinin kontrol grubu seviyesinin 2 katına yakın olduğu anlaşıldı. $100 \mu \mathrm{M}$ SNP uygulaması ise NO miktarının daha fazla artmasını sağladı. $300 \mathrm{mM} \mathrm{NaCl}+100 \mu \mathrm{M}$ SNP uygulaması en yüksek NO miktarı artışına neden oldu. $100 \mu \mathrm{M}$ ABA ve $100 \mu \mathrm{M}$ IAA'nın NO içeriği üzerinde olumlu bir etkiye sahip olduğu anlaşlırken $100 \mu \mathrm{M}$ GA uygulamasının süreye bağlı olarak NO miktarında azalma meydana getirdiği belirlendi (Tablo 1).

Tablo 1. Uygulama gruplarının Helianthus annuss L.cv. TARSAN - 1018 yaprak dokularındaki nitrik oksit miktarı üzerine etkileri

\begin{tabular}{|l|l|l|}
\cline { 2 - 3 } \multicolumn{1}{c|}{} & \multicolumn{2}{l|}{ NO Miktarı $(\mu \mathrm{M}) \bar{x} \pm$ SD } \\
\hline $\begin{array}{l}\text { Uygulama Grupları }(\mathrm{n}=3) \\
\text { (LSD) }\end{array}$ & 24 . Saat & 72. Saat \\
\hline Kontrol & & \\
\hline $300 \mathrm{Mm} \mathrm{NaCl}$ & $\mathrm{a} 2,48 \pm 0,07$ & $\mathrm{a} 2,36 \pm 0,08$ \\
\hline $100 \mu \mathrm{M} \mathrm{SNP}$ & $\mathrm{c} 4,42 \pm 0,07^{*}$ & $\mathrm{~b} 5,52 \pm 0,01^{*}$ \\
\hline $300 \mathrm{mM} \mathrm{NaCl}+100 \mu \mathrm{M} \mathrm{SNP}$ & $\mathrm{f} 9,36 \pm 0,07^{*}$ & $\mathrm{f} 18,33 \pm 0,06^{*}$ \\
\hline $300 \mathrm{mM} \mathrm{NaCl}+100 \mu \mathrm{M}$ ABA & $\mathrm{g} 11,33 \pm 0,08^{*}$ & $\mathrm{~g} 22,55 \pm 0,04^{*}$ \\
\hline $300 \mathrm{mM} \mathrm{NaCl}+100 \mu \mathrm{M}$ IAA & $\mathrm{f} 9,41 \pm 0,01^{*}$ & $\mathrm{e} 14,04 \pm 0,09^{*}$ \\
\hline $300 \mathrm{mM} \mathrm{NaCl}+100 \mu \mathrm{M}$ GA & $\mathrm{d} 5,08 \pm 0,05^{*}$ & $\mathrm{c} 8,05 \pm 0,02^{*}$ \\
\hline $100 \mu \mathrm{M}$ ABA & $\mathrm{c} 4,42 \pm 0,08^{*}$ & $\mathrm{~d} 12,09 \pm 0,08^{*}$ \\
\hline $100 \mu \mathrm{M}$ IAA & $\mathrm{e} 6,96 \pm 0,09^{*}$ & $\mathrm{~d} 12,97 \pm 0,08^{*}$ \\
\hline $100 \mu \mathrm{M}$ GA & $\mathrm{c} 4,34 \pm 0,07^{*}$ & $\mathrm{c} 8,08 \pm 0,01^{*}$ \\
\hline & $\mathrm{b} 3,55 \pm 0,07^{*}$ & $\mathrm{a} 2,42 \pm 0,04$ \\
\hline
\end{tabular}

Tüm uygulama gruplarının kontrol grubuna kıyasla NO miktarında artış sağladığı belirlenirken $100 \mu \mathrm{M}$ GA uygulaması uygulama süresinin artmasıyla NO miktarında azalmaya neden olmuştur ve GA uygulamasının 72. saatinde saptanan NO miktarının kontrol grubuna kıyasla istatistiksel açıdan önemsiz olduğu ( $>>0.05$ ) belirlenmiştir. Bunun dışındaki tüm uygulamaların sağladığı NO miktarının kontrol grubuna kıyasla istatistiksel açıdan önemli olduğu $\left({ }^{*} p<0.05\right.$; Ortalama fark 0.05 düzeyinde önemlidir) belirlenmişstir.

\section{Siklik Guanozin Monofosfat Miktarı}

Uygulama gruplarının cGMP seviyesine etkilerinin değişken olduğu belirlendi. Tüm uygulamalarda elde edilen değerler, kontrol grubuna kıyasla istatistiksel olarak anlamlıydı ( $\mathrm{p}<0.05$ ) (Tablo 2). En yüksek cGMP seviyesi, $300 \mathrm{mM} \mathrm{NaCl}$ uygulamasinin 72 . saatinde (79.75 \pm 1.26 pmol / ml) belirlendi. Tablo 2 incelendiğinde, tüm uygulama gruplarının kontrol grubuna kıyasla daha yüksek bir cGMP seviyesi sağladığı anlaşılmaktadır. En düşük cGMP seviyesi, $100 \mu \mathrm{M}$ ABA'nın 24. saatinde $(13,50 \pm 0,37 \mathrm{pmol} / \mathrm{ml})$ tespit edildi, ancak bu değerin kontrol grubundan yüksek olduğu da gözlendi.

Tüm uygulama gruplarının kontrol grubuna kıyasla cGMP miktarında artış sağladığı belirlenirken $100 \mu \mathrm{M}$ GA ve $100 \mu \mathrm{M}$ IAA uygulamaları uygulama süresinin artmasiyla cGMP miktarinda azalmaya neden olmuştur Tüm uygulamaların sağladığı cGMP miktarının kontrol grubuna kiyasla istatistiksel açıdan önemli olduğu (* $\mathrm{p}<0.05$; Ortalama fark 0.05 düzeyinde önemlidir) belirlenmiştir.

\section{Kalsiyum Miktarı}

Tablo 3'den anlaşılacağ̣ gibi, uygulama gruplarının kalsiyum seviyesindeki etkileri birbirinden farklıdır. $100 \mu \mathrm{M}$ IAA ve $100 \mu \mathrm{M}$ GA haricinde uygulama süresine bağlı olarak $\mathrm{Ca}^{+} \quad 2$ düzeyinin $\operatorname{arttığ~}$ gözlenmiştir. Tüm uygulamaların kontrol grubuna göre daha yüksek bir kalsiyum düzeyine neden olduğu belirlenmiştir (Tablo 3). Uygulama gruplarından elde edilen kalsiyum düzeylerinin kontrol grubuna göre istatistiksel olarak anlamlı olduğu bulundu $(\mathrm{p}<0.05)$ 
Tablo 2. Uygulama gruplarmın Helianthus annuss L.cv. TARSAN - 1018 yaprak dokularındaki cGMP miktarı üzerine etkileri

\begin{tabular}{|l|l|l|}
\hline $\begin{array}{l}\text { Uygulama Grupları }(\mathrm{n}=3) \\
(\mathrm{LSD})\end{array}$ & \multicolumn{2}{l|}{ cGMP Miktarı $(\mathrm{pmol} / \mathrm{ml}) \bar{x} \pm \mathrm{SD}$} \\
\hline & 24. Saat & 72. Saat \\
\hline Kontrol & ${ }^{\mathrm{a}} 6,01 \pm 007$ & $\mathrm{a} 6,12 \pm 0,02$ \\
\hline $300 \mathrm{Mm} \mathrm{NaCl}$ & $\mathrm{d} 23,50 \pm 0,02^{*}$ & $\mathrm{i} 79,75 \pm 1,26^{*}$ \\
\hline $100 \mu \mathrm{M}$ SNP & $\mathrm{h} 51,06 \pm 1,07^{*}$ & $\mathrm{~h} 75,17 \pm 1,82^{*}$ \\
\hline $300 \mathrm{mM} \mathrm{NaCl}+100 \mu \mathrm{M}$ SNP & $\mathrm{l} 59,03 \pm 0,96^{*}$ & $65,039 \pm 0,23^{*}$ \\
\hline $300 \mathrm{mM} \mathrm{NaCl}+100 \mu \mathrm{M} \mathrm{ABA}$ & $\mathrm{c} 16,10 \pm 0,05^{*}$ & $\mathrm{~b} 16,57 \pm 0,09^{*}$ \\
\hline $300 \mathrm{mM} \mathrm{NaCl}+100 \mu \mathrm{M}$ IAA & $\mathrm{g} 37,25 \pm 0,36^{*}$ & $\mathrm{~g} 52,26 \pm 0,96^{*}$ \\
\hline $300 \mathrm{mM} \mathrm{NaCl}+100 \mu \mathrm{M}$ GA & $\mathrm{d} 24,75 \pm 1,06^{*}$ & $\mathrm{f} 46,33 \pm 1,36^{*}$ \\
\hline $100 \mu \mathrm{M}$ ABA & $\mathrm{b} 13,50 \pm 0,37^{*}$ & $\mathrm{e} 26,03 \pm 0,58^{*}$ \\
\hline $100 \mu \mathrm{M}$ IAA & $\mathrm{f} 31,03 \pm 0,58^{*}$ & $\mathrm{~d} 24,75 \pm 0,73^{*}$ \\
\hline $100 \mu \mathrm{M}$ GA & $\mathrm{e} 29,79 \pm 0,44^{*}$ & $\mathrm{c} 18,56 \pm 0,72^{*}$ \\
\hline
\end{tabular}

Tablo 3. Uygulama gru”plarının Helianthus annuss L.cv. TARSAN - 1018 yaprak dokularındaki $\mathrm{Ca}^{+2}$ miktarı üzerine etkileri

\begin{tabular}{|l|l|l|}
\hline $\begin{array}{l}\text { Uygulama Grupları }(\mathrm{n}=3) \\
(\mathrm{LSD})\end{array}$ & \multicolumn{2}{|l|}{$\mathrm{Ca}^{+2}$ Miktarı $(\mu \mathrm{g} / \mu \mathrm{l}) \bar{x} \pm \mathrm{SD}$} \\
\hline & 24. Saat & 72. Saat \\
\hline Kontrol & $\mathrm{a} 1,72 \pm 0,17$ & $\mathrm{a} 1,46 \pm 0,12$ \\
\hline $300 \mathrm{Mm} \mathrm{NaCl}$ & $\mathrm{c} 4,59 \pm 0,4^{*}$ & $\mathrm{c} 4,96 \pm 0,06^{*}$ \\
\hline $100 \mu \mathrm{M} \mathrm{SNP}$ & $\mathrm{b} 3,38 \pm 0,17^{*}$ & $\mathrm{c} 4,43 \pm 0,02^{*}$ \\
\hline $300 \mathrm{mM} \mathrm{NaCl}+100 \mu \mathrm{M} \mathrm{SNP}$ & $\mathrm{c} 4,14 \pm 0,36^{*}$ & $\mathrm{c} 4,45 \pm 0,03^{*}$ \\
\hline $300 \mathrm{mM} \mathrm{NaCl}+100 \mu \mathrm{M}$ ABA & $\mathrm{d} 5,03 \pm 0,01^{*}$ & $\mathrm{~d} 5,06 \pm 0,12^{*}$ \\
\hline $300 \mathrm{mM} \mathrm{NaCl}+100 \mu \mathrm{M} \mathrm{IAA}$ & $\mathrm{b} 3,23 \pm 0,06^{*}$ & $\mathrm{c} 4,84 \pm 0,07^{*}$ \\
\hline $300 \mathrm{mM} \mathrm{NaCl}+100 \mu \mathrm{M} \mathrm{GA}$ & $\mathrm{c} 4,03 \pm 0,16^{*}$ & $\mathrm{~d} 5,44 \pm 1,04^{*}$ \\
\hline $100 \mu \mathrm{M} \mathrm{ABA}$ & $\mathrm{e} 7,20 \pm 0,08^{*}$ & $\mathrm{e} 7,99 \pm 0,01^{*}$ \\
\hline $100 \mu \mathrm{M} \mathrm{IAA}$ & $\mathrm{b} 3,13 \pm 0,03^{*}$ & $\mathrm{~b} 3,11 \pm 0,07^{*}$ \\
\hline $100 \mu \mathrm{M} \mathrm{GA}$ & $\mathrm{e} 7,77 \pm 0,03^{*}$ & $\mathrm{~d} 5,50 \pm 0,02^{*}$ \\
\hline
\end{tabular}

Tüm uygulama gruplarının kontrol grubuna kıyasla $\mathrm{Ca}^{+2}$ miktarında artış sağladığ GA ve $100 \mu \mathrm{M}$ IAA uygulamaları uygulama süresinin artmasıyla $\mathrm{Ca}^{+2}$ miktarında azalmaya neden olmuştur Tüm uygulamaların sağladığ $\mathrm{Ca}^{+2}$ miktarının kontrol grubuna kıyasla istatistiksel açıdan önemli olduğu $\left({ }^{*} \mathrm{p}<0.05\right.$; Ortalama fark 0.05 düzeyinde önemlidir) belirlenmiştir.

\section{TARTIŞMA ve SONUÇ}

$\mathrm{Bu}$ çalışmanın sonucunda, nitrik oksit (NO) düzeyinin $100 \mu \mathrm{M}$ GA uygulaması dışındaki uygulamalarda zamana bağlı olarak arttığ Literatüre göre; NO, stres koşullarında adaptasyon mekanizmasını düzenlemeye yardımcı olan bir moleküldür. Bu rol, NO'nun bir sinyal molekülü olarak işlev gördüğü fikrini düşündürmektedir. NO'nun jasmonik asit sentezini azalttığı, hidrojen peroksit sentezini arttırdığ 1 ve abiyotik stres toleransı dahil bazı genlerin ekspresyonunu düzenlediği bildirilmiştir (Orozco-Cardenas ve Ryan, 2002; Wendehenne ve ark., 2004). NaCl uygulaması ile NO seviyesinde bir artış olduğu ve bu artışın $\mathrm{NaCl}$ uygulamasının devam etmesiyle sürdürüldüğü tespit edildi. Ortaya çıkan stres koşullarında NO seviyesindeki artışın, stres koşullarına adaptasyon mekanizmasını desteklediği düşünülmektedir. Mevcut sonuç literatürler ile uyumludur (Orozco-Cardenas ve Ryan, 2002; Wendehenne ve ark., 2004; Zhao ve ark., 2004). Giberellik asit uygulamasının ciddi derecede NO depresyonuna neden olduğu ve bu durumun kısmen de olsa, NO donörü S-nitrosoglutatyon (GSNO) uygulanarak düzeltilebileceği belirtilmiştir (Zhu ve ark., 2012). Mevcut çalışmada Gibberelik asit uygulaması zamanına bağlı olarak NO düzeyini azaltmıştır. Her ne kadar GA tek başına NO seviyesini düşürmüşse de, $\mathrm{NaCl}$ ile kullanımı $\mathrm{NO}$ seviyesinde artış sağlamıştır. Bu durum, stres koşullarından dolayı NO seviyesinin artmasıyla açıklanabilir. Öte yandan ABA ve IAA uygulamalarının, kontrol grubuna kıyasla, NO düzeyini artırdığı belirlenmiştir (Tablo 1). Salatalık köklerinde IAA uygulamasının, ciddi miktarda NO birikimi sağladığı bildirilmiştir (Gong ve ark., 2014). Mevcut çalışmada IAA uygulaması, NO miktarında artış sağlamıştır. cGMP bir sinyal molekülüdür. $\mathrm{Bu}$ çalışmada stres koşullarına bağlı 
olarak $\mathrm{NaCl}$ uygulamasının cGMP düzeyini artırdığı gözlemlenmiştir. cGMP'deki artış stres zamanına bağlı olarak devam etmiştir. Araştırmacılar tuzluluk ve ozmotik stres koşullarında farklı cGMP değerlerini belirlediklerini ve bu değerlerin 5 saniye gibi kısa sürede arttığını bildirmişlerdir (Donaldson ve ark., 2004). Literatürde NO ve cGMP arasındaki ilişki hakkında bilgi bulunmaktadır (She ve ark., 2004; Neill ve ark., 2007; Wang ve ark., 2010a; Montillet ve ark., 2012). Neill ve ark., (2003) cGMP sentezinin bitkilerde bulunduğunu ve cGMP sentezinin NO tarafından teşvik edildiğini bildirmiştir. Mevcut çalışmanın sonuçları literatürle uyumludur. Bitki hormonları kontrol grubuna kiyasla 24. saatte cGMP seviyesini artırmış ancak 72. saatte $100 \mu \mathrm{M}$ IAA ve $100 \mu \mathrm{M}$ GA uygulamaları cGMP düzeyini düşürmüştür. $100 \mu \mathrm{M}$ ABA uygulaması, uygulama süresine bağlı olarak cGMP düzeyinde artış sağlamıştır. Bu sonuçlar; cGMP ve bitki hormonları arasında bir etkileşim olduğunu göstermektedir. Ek olarak; Arpa alevron hücrelerindeki ABA uygulamasının cGMP seviyesinde herhangi bir değişikliğe neden olmadığ $\breve{l a}_{1}$ bildirilmiştir (Penson ve ark., 1996). Benzer şekilde, araştırmacılar, ABA'nın Arabidopsis mezofil hücrelerinde cGMP seviyesine herhangi bir etkisi bulunmadığını da ifade etmiştir (Wang ve ark., 2010). Mevcut çalışmada, ABA uygulamasının cGMP düzeyini arttırdığı saptanmış olup, çalışmalarda kullanılan materyallerin farklı olması bunun bir nedeni olabilir. Buna ek olarak, ABA'nın cGMP miktarını arttırdığ ve ABA ile cGMP arasında direkt bir bağlantı olmadığ $\breve{l}_{1}$ da bildirilmiştir (Isner ve ark., 2012). GA uygulamasinin cGMP ve sitosolik cGMP düzeyini arttırdığı belirtilmiştir (Penson ve ark., 1996). Yaptığımız çalışmada, GA'nın kontrol grubuna kıyasla cGMP düzeyini arttırdığı saptanmıştır. IAA uygulamasinin Arabidopsis protoplastında cGMP sinyalini arttırdığı bildirilmiştir (Isner ve ark., 2012). Elde edilen sonuçlar literatürle benzerdir.

Kalsiyum iyonu $\left(\mathrm{Ca}^{+2}\right)$, bitkilerde birçok sinyal iletim yolunda yer alan en önemli hücre içi ikincil haberci moleküllerinden biridir. Sitosolik olmayan $\mathrm{Ca}^{+2}$ konsantrasyonunun patojen, bitki hormonları, yüksek tuzluluk, soğuk ve kuraklık gibi abiyotik streslere karşı bazı fizyolojik uyaranlara yanıt olarak arttığ belirtilmiştir (Tuteja, 2007). Sonuçlar, uygulama gruplarında kontrol grubuna kıyasla $\mathrm{Ca}^{+2}$ miktarının arttığını göstermektedir. Tuz stresine bağlı olarak $\mathrm{Ca}^{+2}$ düzeyi artmıştır. Benzer şekilde SNP, ABA, IAA ve GA uygulamaları $\mathrm{Ca}^{+2}$ düzeyinde artış sağlamıştır. Araştırmacılar; ABA, kuraklık, yüksek tuzluluk ve soğuk streslerinin bitki hücrelerindeki kalsiyum düzeyini hızla arttırdığını belirtmektedir (Swamy ve Smith, 1999; Xiong ve ark., 2002; Chinnusamy ve ark., 2004; Mahajan ve Tuteja, 2005). Abd El-Samad (2013), farklı tuz stresi koşullarındaki Triticum vulgaris $\mathrm{L}$. fide ve köklerinde $\mathrm{GA}_{3}$ ve IAA uygulamalarmnn $\mathrm{Ca}^{+2}$ düzeylerini değiştirdiğini göstermiştir. Araştırmacı, $\mathrm{GA}_{3}$ ve IAA uygulanan gruplardaki $\mathrm{Ca}^{+2}$ düzeylerinin, $\mathrm{GA}_{3}$ ve IAA uygulaması yapılmayanlara göre arttığını bildirmiştir. Sonuçlarımız literatür ile benzerlik göstermektedir.

Sonuç olarak; tuz stresi, SNP ve hormon uygulamalarının bazı sinyal molekülleri üzerine etkilerinin araştırıldığı bu çalışmada NO, cGMP ve $\mathrm{Ca}^{+2}$ 'nin stres koşullarına karşı düzenlendiği gözlenmiştir. Hormon uygulamaları, stres başlangıcında hızlı sinyal tepkileri sağlarken, devam eden stres koşullarında sinyal molekülleri üzerindeki etkileri sınırlı kalmıştır. Öte yandan, tüm uygulamaların kontrol grubuna kıyasla daha yüksek sinyal molekül düzeyleri sağladığı belirlenmiştir. Bütün bu sonuçlar, hormonlar ve sinyal molekülleri arasında sinerjistik bir etki olduğunu göstermektedir. NO donörü SNP uygulamasının cGMP miktarında artış sağlaması, NO ile cGMP arasında yakın ilişki olduğunu göstermektedir. Bezer şekilde SNP uygulaması $\mathrm{Ca}^{+2}$ miktarında da artış sağlamıştır. Elde edilen tüm sonuçlar liteatürler ile birlikte düşünüldüğünde; Helianthus annuus L. cv. TARSAN1018 ayçiçeği bitkisi yapraklarında strese karşı sinyal moleküllerinin birlikte hareket ettiği, hormonların sinyal molekülleri üzerine etkilerinin bulunduğu, sinyal cevaplarının düzenlenmesinde bitkinin içsel uyum ve savunma mekanizmalarının karmaşı tepkiler vererek olumsuz durumlardan korunmaya çalıştığ çalışmalarda, diğer bitki büyüme düzenleyicilerin farklı sinyal molekülleri üzerindeki etkilerinin ortaya konulmasının, mekanizmanın anlaşılmasına yardımcı olacağı düşünülmektedir.

\section{TEŞEKKÜR}

$\mathrm{Bu}$ araştırma, Bitlis Eren Üniversitesi Bilimsel Araştırma Projeleri Birimi (BEBAP) tarafindan desteklenmiştir (Proje no: 2015/04).

\section{KAYNAKLAR}

Abd El-Samad, HM 2013. The physiological response of wheat plants to exogenous application of gibberellic acid (GA3) or indole-3-acetic acid (IAA) with endogenous ethylene under salt stress conditions. In International Journal of Plant Physiology and Biochemistry, 5(4): 58-64

Beligni MV, Lamattina L 2000. Nitric oxide stimulates seed germination, deetiolation, and inhibits hypocotyl elongation, three lightinducible responses in plants. Planta, 210: 215-221.

Chinnusamy V, Schumaker K, Zhu JK 2004. Molecular genetic perspectives on cross-talk and specificity in abiotic stress signaling in plants. Journal of Experimentha Botany, 55:225-236.

Davies PJ, 1995. Plant Hormones, Dordrecht. Kluwer Academic Publishers, The Netherlands. 
Davies WJ, Jones HG, 1991. Abscisic acid: physiology, biochemistry. BIOS. Scientific Publishers Ltd., Cambridge, UK.

Donaldson L, Ludidi N, Knight MR, Gehring C, Denby $\mathrm{K}$ 2004. Salt and osmotic stress cause rapid increases in Arabidopsis thaliana cGMP levels. FEBS Letters, 569: 317-320.

Gaspar T, Franck T, Bisbis B, Kevers C, Jouve L, Hausman JF, Dommes J 2002. Concepts in plant stress physiology. Application to plant tissue cultures. Plant Growth and Regulation, 37: 263285.

Gong B, Miao L, Kong W, Bai JG, Wang X, Wei M, Shi Q 2014. Nitric oxide, as a downstream signal, plays vital role in auxin induced cucumber tolerance to sodic alkaline stress. Plant Physiology and Biochemistry, 83: 258-266.

Guo FQ, Crawford NM 2005. Arabidopsis nitric oxide synthase 1 is targeted to mitochondria and protects against oxidative damage and dark-induced senescence. Plant Cell, 17: 3436-3450.

Hancock JT, Neill SJ, Wilson ID 2011. Nitric oxide and ABA in the control of plant function. Plant Science, 181: $555-559$.

Hasanuzzaman M, Nahar K, Fujita M 2013. Plant Response to Salt Stress and Role of Exogenous Protectants to Mitigate Salt-Induced Damages. In: Ahmad P, Azooz M, Prasad M. (eds) Ecophysiology and Responses of Plants under Salt Stress. Springer, New York, NY

He YK, Xue WX, Sun YD, Yu XH, Liu PL 2000. Leafy head formation of the progenies of transgenic plants of Chinese cabbage with exogenous auxin genes. Cell Research, 10: 151-602.

Isner JC, Nuhse T, Maathuis FJM 2012. The cyclic nucleotide cGMP is involved in plant hormone signalling and alters phosphorylation of Arabidopsis thaliana root proteins. Journal of Experimental Botany, 63(8):3199-3205.

Jaleel AC, Manıvannan P, Wahid A, Farooq M, AlJuburi HJ, Somasundaram R, Panneerselvam R 2009. Drought Stress in Plants: A Review on Morphological Characteristics and Pigments Composition. International Journal of Agriculture and Biology, 11:1.

Jones HG, Jones MB 1989. Introduction: some terminology and common mechanisms, in: Jones HG, Flowers TJ, Jones MB (Eds.), Plants Under Stress, Cambridge university Press, Cambridge.

Jung J, Park C 2011. Auxin modulation of salt stress signaling in Arabidopsis seed germination. Plant Signaling \& Behavior, 6: 1198-1200.

Kim SG, Park CM 2008. Gibberellic acid-mediated salt signaling in seed germination. Plant Signaling \& Behavier, 3:877-879.

Leshem YY, Wills RBH, Ku VVV 1998. Evidence for the function of the free radical gas-nitric oxide (NO)-as an endogenous maturation and senescence regulating factor in higher plants. Plant Physiology and Biochemistry, 36: 825-833.

Libourel IG, Bethke PC, De Michele R, Jones RL 2006. Nitric oxide gas stimulates germination of dormant Arabidopsis seeds: use of a flow-through apparatus for delivery of nitric oxide. Planta, 223: 813-820.

Magome H, Yamaguchi S, Hanada A, Kamiya Y, Odadoi K 2004. Dwarf and delayed- flowering 1, a novel Arabidopsis mutant deficient in gibberellins biosynthesis because of overexpression of a putative AP2 transcription factor. Plant Journal, 37:720 729

Mahajan S, Tuteja N 2005. Cold, salinity and drought stresses: An overview. Archives of Biochemistry and Biophysics, 444:139-158.

Martinez-Ferri E, Manrique E, Valladares F, Balaguer L 2004. Winter photoinhibition in the field involves different processes in four co-occurring Mediterranean tree species. Tree Physiology, 24: 981-990.

Mishina TE, Lamb C, Zeier J 2005. Expression of a nitric oxide degrading enzyme induces a senescence programme in Arabidopsis. Plant Cell \& Environment, 30: 39-52.

Montillet JL, Chamnongpol S, Rustérucci C, Dat J, Van de Cotte B, Agnel JP, Battesti C, Inzé D, Breusegem FV, Triantaphylides C 2005. Fatty acid hydroperoxides and $\mathrm{H}_{2} \mathrm{O}_{2}$ in the execution of hypersensitive cell death in tobacco leaves, Plant Physiology, 138:1516-1526.

Moore TC, 1989. Biochemistry and Physiology of Plant Hormones, 2nd edn. Springer-Verlag, New York U.S.A.

Narusaka Y, Nakashima K, Shinwari ZK, Sakuma Y, Furihata T, Abe H, Narusaka M, Shinozaki K, Yamaguchi-Shinozaki K 2003. Interaction between two cisacting elements, ABRE and DRE, in ABAdependent expression of Arabidopsis rd29A gene in response to dehydration and high-salinity stresses. Plant Journal, 34: 137-148.

Neill S, Barros R, Bright J, Desikan R, Hancock J, Harrison J, Morris P, Ribeiro D, Wilson I 2008. Nitric oxide, stomatal closure, and abiotic stress, Journal of Experimental Botany, 59: 165-176.

Neill S, Bright J, Hancock J, Harrison J, Barros R, Desikan R, Riberio D 2007. Nitric oxide, stomatal closure and abiotic stress. Comparative Biochemistry and Physiology, Part A, 146: S255S266.

Neill SJ, Desikan R, Hancock JT 2003. Nitric Oxide Signaling in Plants. New Phytologist, 159: 11-35.

$\mathrm{Ni} \mathrm{D}$, Yu XH, Wang LJ, Xu ZH 2002. Aberrant development of pollen in transgenic tobacco expressing bacterial iaaM gene driven by pollen and tape tum-specific promoters. Acta Biologica Experimenta Sinica, 35: 1-6.

Orozco-Cardenas ML, Ryan CA, 2002. Nitric oxide negatively modulates wound signaling in tomato 
plants. Plant Physiology, 130: 487- 493.

Parida AK, Das AB 2005. Salt tolerance and salinity effects on plants: A review. Ecotoxicology and Environmental Safety, 60(3): 324-349

Penson SP, Schuurink RC, Fath A, Gubler F, Jacobsen JV, Jones RL 1996. cGMP is required for gibberellic acidinduced gene expression in barley aleurone. Plant Cell, 8:2325-2333

Popko J, Hänsch R, Mendel R, Polle A, Teichmann T 2010. The role of abscisic acid and auxin in the response of poplar to abiotic stress. Plant Biology, $12,242-258$.

Radhakrishnan R, Lee IJ 2013. Spermine promotes acclimation to osmotic stress by modifying antioxidant, abscisic acid, and jasmonic acid signals in soybean. Journal of Plant Growth and Regulation, 32: 22-30.

Ribaut JM, Pilet PE 1991. Effect of water stress on growth, osmotic potential and abscisic acid content of maize roots. Physiologia Plantarum, 81:156-162.

She XP, Song XG, He JM 2004. Role and relationship of nitric oxide and hydrogen peroxide in light/darkregulated stomatal movement in Vicia faba. Acta Botanica Sinica, 46: 1292-1300.

Swamy PM, Smith B 1999. Role of abscisic acid in plant stress tolerance. Current Science, 76:12201227.

Szepesi A, Csiszar J, Gemes K, Horvarth E, Horvath F, Simon LM, Tari I 2009. Salicylic acid improves the acclimation to salt stress by stimulating abscisic aldehyde oxidase activity and abscisic acid accumulation, and increases $\mathrm{Na}^{+}$contents of the leaves without toxicity symptoms in Solanum lycopersicum L. Journal of Plant Physiology, 166: 914-925.

Tuteja N, 2007. Abscisic acid and abiotic stress signaling. Plant Signaling \& Behavier, 2:135-138.

Valladares F, Pearcy RW 2002. Drought can be more critical in the shade than in the sun: a field study of carbon gain and photo-inhibition in a Californian shrub during a dry El Nino year. Plant Cell \& Environment, 25, 749-759.

Wang H, Zhang S, Zhang W, Wei C, Wang P 2010. Effects of nitric oxide on the growth and antioxidant response of submerged plants Hydrilla verticillata (L.f.) Royle. African Journal of Biotechnology, 9(44): 7470-7476.

Wang X, Li J, Liu J, He W, Bi Y 2010. Nitric oxide increases mitochondrial respiration in a cGMPdependent manner in the callus from Arabidopsis thaliana, Nitric Oxide, 23: 242-250.

Wendehenne D, Durner J, Klessig DF, 2004. Nitric oxide: a new player in plant signalling and defence responses. Current Opinion in Plant Biology, 7: 449-455.

Weyers JDB, Paterson NW 2001. Plant hormones and the control of physiological processes. New Phytol. 152: 375-407.

Xiong L, Schumaker KS, Zhu JK 2002. Cell signaling during cold, drought, and salt stress. The Plant Cell, 14:165-183.

Yordanov I, Velikova V, Tsonev T 2000. Plant responses to drought, acclimatation and stress tolerance. Photosynthetica, 38, 171-186.

Zhao L, Zhang F, Guo J, Yang Y, Li B, Zhang L 2004. Nitric oxide functions as a signal in salt resistance in the calluses from two ecotypes of reed. Plant Physiol. 134: 849-857.

Zhao MG, Tian QY, Zhang WH, 2007. Nitric oxide synthasedependent nitric oxide production is associated with salt tolerance in Arabidopsis. Plant Physiology, 144: 206-217.

Zhu JK, 2007. Plant Salt Stress: John Wiley \& Sons, Ltd.

Zhu XF, Jiang T, Wang ZW, Lei GJ, Shi YZ, Li GX, Zheng SJ, 2012. Gibberellic acid alleviates cadmium toxicity by reducing nitric oxide accumulation and expression of IRT1 in Arabidopsis thaliana. Journal of Hazardous Material, 239:302-307. 